\title{
Effects of Water Flow from the Xylem on the Growth-induced Water Potential and the Growth-effective Turgor Associated with Enlarging Tomato Fruit
}

\author{
Md. Mokter Hossain ${ }^{1}$ and Hiroshi NonAmI ${ }^{1,2}$ \\ 'The United Graduate School of Agricultural Sciences, Ehime University, \\ Tarumi, Matsuyama 790-8566, Japan \\ ${ }^{2}$ Plant Biophysics/Biochemistry Research Laboratory, Faculty of Agriculture, Ehime University, \\ Tarumi, Matsuyama 790-8566, Japan
}

(Received May 7, 2010)

\begin{abstract}
Intact tomato (Solanum lycopersicum L.) fruit growth was monitored while heat-girdling treatment was conducted. Heat-girdling treatments revealed that most water flow into enlarging fruit of tomato plants originated from the xylem throughout fruit growth periods. After measuring the water status and growth rates simultaneously, the growth parameters of Lockhart's equation were determined in expanding fruit of tomato plants. During the early stage of fruit growth, when the growth-induced water potential was obtained by calculating the difference between water potentials of the growing region and the water source, it was found that sizes of the growthinduced water potential and the hydraulic conductance were predominant factors to regulate cell expansion. When fruit became almost mature, sizes of the growth-effective turgor and the wall extensibility were primary factors to regulate cell expansion, but not the water potential gradients. Such changes in water flow from the xylem related to enlarging processes of fruit may explain how fruit cracking takes place right before fruit maturation.
\end{abstract}

Keywords : cell wall extensibility, heat girdling, hydraulic conductivity, Solanum lycopersicum L., turgor

\section{INTRODUCTION}

Unlikely to leaves and stems, tomato fruit has a low transpiration rate (Shirazi and Cameron, 1993; Leonardi et al., 1999, 2000). When tomato fruit surface was checked with scanning electron microscopy, no stomata were found (Leonardi et al., 1999). Although fruit growth is obviously related to water relations, there are a few reports about the relationship between fruit growth and water relations. It is well known that tomato fruit tends to suffer from fruit cracking frequently just before maturation although fruit cracking has not observed when fruit is immature (Saito, 1989; Ikeda et al., 1999b). Immediately after completion of flowering and pollination, cell division in tomato fruit is mostly over (Houghtaling, 1935; Saito, 1989). Thus, growth of tomato fruit after flowering can be considered to be solely due to cell expansion. When fruit cracking takes place, absorption of water due to cell expansion and force exerted in fruit may not be well balanced, resulting in excessive expansion in mesocarp tissue. Because tissues in tomato fruit grow mostly by enlarging cells after completion of cell division, water may enter too rapidly into the enlarging cells

Corresponding author: Hiroshi Nonami, fax : +81-89-946-9824, e-mail : nonami@agr.ehime-u.ac.jp 
when fruit cracks.

Shackel et al. (1991) reported that a decrease in turgor of tomato pericarp occurred during ripening by using the pressure probe technique and this may result from the presence of apoplastic solutes. The relationship between bulk turgor and fruit expansion was determined in growing young tomato fruit by incubation in solutions of varying osmotic concentrations (Grange, 1995). Steudle and Wieneke (1985) observed that elastic and hydraulic properties of cells changed during fruit development in apples. However, in their system, turgor was artificially modified by manipulating the osmotic potential of the bathing medium (Steudle and Wieneke, 1985). Their measurement of osmotic potential depended on immersion of tissue segments in concentrated solutions and determination of the solution water potential prevented enlargement (Steudle and Wieneke, 1985). This approach suffers from problems due to penetration of tissues in the solutions for long time, and then there are many criticisms of this measurement (Cosgrove, 1993). To our knowledge, there are no previous reports of analyzing fruit growth by applying Lockhart's equation during the growing stage. Because fruit usually softens and accumulate soluble solids (sugars, organic acids and amino acids etc.) as fruit develops, predominant growth-control parameters for water relations must be changed during the growth stages.

The mechanisms of cell enlargement of plant cells requires high enough turgor to extend the cell walls and the persistent differences in water potential between growing tissue and the water source to provide water for the enlargement process. The steady relative growth rate $(G$; unit: $\mathrm{s}^{-1}$ ) of tissue enlargement can be related to the averaged wall extensibility ( $m$; unit: $\left.\mathrm{s}^{-1} \mathrm{MPa}^{-1}\right)$ and the averaged turgor $\left(\Psi_{p}\right.$; unit: MPa) that extends the cell walls outward by the following equation (Green et al., 1971);

$$
G=m\left(\Psi_{p}-Y\right)
$$

where $Y$ (unit: MPa) is the yield threshold turgor below which the force on the wall is too small to enlarge the wall irreversibly. Thus, $\left(\Psi_{p}-Y\right)$ is the growth-effective turgor.

In many growing tissues, the steady rate of water uptake necessary to support cell enlargement can be determined by the average hydraulic conductance $\left(L\right.$; unit: $\left.\mathrm{s}^{-1} \mathrm{MPa}^{-1}\right)$ and the growthinduced water potential $\left(\Psi_{w}-\Psi_{o}\right)$ obtained from average water potential difference between elongating cells $\left(\Psi_{w}\right)$ and the water source $\left(\Psi_{o}\right)$ (Ikeda et al., 1999a). The relationship can be expressed as;

$$
G=L\left(\Psi_{w}-\Psi_{o}\right)
$$

As water uptake and cell wall extension simultaneously occur, Equations 1 and 2 can be combined by the relation of $\Psi_{w}=\Psi_{s}+\Psi_{p}$ assuming that water potential in cytoplasm is locally equilibrated with that in the wall space (Molz and Boyer, 1978; Nonami and Boyer, 1987). Hence,

$$
G=\frac{m L}{m+L}\left(\Psi_{o}-\Psi_{s}-Y\right)
$$

This equation is known as Lockhart's combined equation governing cell enlargement (Lockhart, 1965a, 1965b) and showing both the effects of wall extensibility and water conductance. Since it is difficult to determine all parameters in Equation 3 simultaneously, Ikeda et al. (1999a) rearranged Equation 3 as follows:

$$
\frac{G}{m}+\frac{G}{L}=\left(\Psi_{o}-\Psi_{w}\right)+\left(\Psi_{p}-Y\right)
$$

This equation is shown that parameters of $\left(\Psi_{o}-\Psi_{w}\right)$ and $\left(\Psi_{p}-Y\right)$ are lineally separated.

This work was undertaken to make it clear whether the growth-effective turgor and the growth-induced water potential respond to enlarging tomato fruit. 


\section{MATERIALS AND METHODS}

Tomato seeds (Solanum lycopersicum L. cv. Momotaro) were disinfected with 5\% NaOCl solution for $15 \mathrm{~min}$, and rinsed with distilled water. Tomato seeds were germinated in a petri dish at $25 \pm 1^{\circ} \mathrm{C}$. After tomato seeds were germinated, they were sown in vermiculite grown for 6 days by fertilizing with $0.10 \mathrm{~S} \cdot \mathrm{m}^{-1}$ of the modified Hoagland solution (Nonami and Schulze, 1989). Subsequently, the seedlings were grown hydroponically in a glass house under natural sunlight. The concentration of the hydroponic solution was adjusted to $\mathrm{pH} 6.0^{-} 6.5$ and $0.10 \mathrm{~S} \cdot \mathrm{m}^{-1}$ that is equivalent to $-0.05 \mathrm{MPa}$ of water potential. When tomato plants had 9 leaves, the concentration of the hydroponic solution was increased to $0.15 \mathrm{~S} \cdot \mathrm{m}^{-1}$ that is equivalent to $-0.08 \mathrm{MPa}$ of water potential. The maximum temperature was $38^{\circ} \mathrm{C}$, and the minimum temperature was $15^{\circ} \mathrm{C}$ during the experiment. Relative humidity (RH) ranged from 60 to $97 \%$. The experiment was conducted between February 15, 2008 and June 30, 2008. Fruits were picked after size measurement, and then immediately transferred to laboratory for water status measurement. Fruit was covered with a vinyl bag $(150 \times 350 \mathrm{~mm}, 0.018 \mathrm{~mm}$ thick $)$ containing a sheet of wet tissue paper to prevent transpiration from peel in the evening before the sampling day.

\section{Growth measurement}

Fruit: The vertical and horizontal diameters and height of fruit were measured with a digital caliper (DIGI-KANON EMA-20, Nakamura Mfg. Co., Ltd., Tokyo, Japan). Fruit volume was estimated by using the equation for an ellipsoid, i.e.,

$$
V=\frac{4}{3} \pi \cdot a b c
$$

where $a, b$ and $c$ are the lengths of the semiaxes of the ellipsoid.

The relative growth rate (RGR) was determined from changes in fruit volume as a function of time, i.e.,

$$
\mathrm{RGR}=\frac{1}{\mathrm{~V}\left(\mathrm{~T}_{1}\right)} \cdot \frac{\mathrm{V}\left(\mathrm{T}_{2}\right)-\mathrm{V}\left(\mathrm{T}_{1}\right)}{\mathrm{T}_{2}-\mathrm{T}_{1}}
$$

where $\mathrm{V}\left(\mathrm{T}_{1}\right)$ and $\mathrm{V}\left(\mathrm{T}_{2}\right)$ are fruit volume measured at time $\mathrm{T}_{1}$ and time $T_{2}$, respectively.

Fruit weight was measured with electric balances (E1200S and R200D, Sartorius, Tokyo) before fruit volume was measured.

After measurements of sizes of fruit, fruit was cut into several pieces, and the excised pieces were put into water contained in a graduated cylinder. Fruit volume was measured by displaced volume of water in the graduated cylinder.

Enlargement of tomato fruit was measured directly with a rotary variable differential transformer (R30, Schaevitz Engineering, Pennsauken, NJ 08110, USA). The transformer was mounted on a Z-axis micro-stage (LV-241, Chuo Precision Industrial Co., Ltd., Tokyo, Japan) having a micrometer with $2 \mu \mathrm{m}$-graduations over the displacement range of $2 \mathrm{~mm}$ long. Further, the z-axis micro-stage was fixed on a microscope stand which allowed of the movement of the micro-stage over $220 \mathrm{~mm}$ ranges in the z-direction with the accuracy of $10 \mu \mathrm{m}$. Hence, the position of the rotary variable differential transformer could be adjusted freely in the z-direction, and additionally, calibration could be carried out with the micrometer at any time without disturbing the plant materials. A tomato fruit was selected for growth measurement and the other fruits in the same fruit truss were excised from the plant 3 days prior to the experiment. A tomato plant was fixed to a vertical metal pole attached to the microscope stand at 3 places with horizontal metal bars with the help of cloth adhesive tape so that its fruit could be connected to the rotary variable differential transformer. The head of T-shaped metal pin was connected at the tip of the fruit with adhesive tape, 
and the tail of the pin was cramped with an aluminum bar attached to the rotary variable differential transformer. The weight of the pin was balanced with a weight attached to the other side of bar so that the fruit did not experience any additional weight during the growth measurement. The fruit was set on the transformer at 6:00 a.m., and it was allowed to grow freely during the daytime. The output of the transformer was recorded as the displacement in length with a chart recorder (SS250F Recorder, SEKONIC Co., Tokyo, Japan) from 23:00. When the slope of the displacement curve was stable about a few hours after recording, a jet of hot water steam $\left(98^{\circ} \mathrm{C}\right)$, which was produced with boiling water nearby the plant, was sprayed over peduncle tissue of the fruit for $5 \mathrm{~min}$. After the steam treatment, tissue of peduncle exposed to the hot steam was doped completely with organic glue containing $40-50 \%$ of cyclohexanone and $35-45 \%$ of methylethylketone (Hishi-Bond A, Mitsubishi Plastics, Inc., Tokyo, Japan). During and after phloem tissue killing treatment with hot steam and organic glue, the growth was recorded continuously with the recorder. When the slope of the displacement in length became stable after a few hours of recording, then, the peduncle at the treatment location was cut by a pair of scissors. During the growth measurement with the rotary variable differential transformer, the experiment was conducted from 23:00 to 6:00 in a greenhouse so that the effect of transpiration on growth was minimized. In the growth measurement, the air temperature and humidity ranged from 21.1 to $23.4^{\circ} \mathrm{C}$ and from 85 to $98 \% \mathrm{RH}$, respectively, and the air temperature and relative humidity were measured continuously and recorded electronically with a thermo-recorder (RSH-1010, TABAI ESPEC Corp., Osaka, Japan).

Fruit pedicels: The diameter of pedicel, which was measured at the middle of the most adjacent internode of a flower/fruit and having the narrowest width, was measured with the digital caliper. A peduncle connected to the pedicel was excised, re-cut under distilled water and placed its cut end in a solution of safranin $(0.05 \%$, w/v), while a flower/fruit was attached. After $2.5 \mathrm{~h}$, the safranin was absorbed by the water-conducting xylem, whose lignin in the walls was stained. Free hand sections were made at the middle of the pedicel. The fresh sections were mounted in water, viewed under a microscope (IMT-2; Olympus Optical Co., Ltd., Tokyo, Japan), and their images together with a micrometer image were taken with a digital camera (Nikon COOLPIX 2500, Nikon Corp., Tokyo, Japan). Then, the images were stored in a personal computer (PC), and sizes and numbers of xylem vessels were counted manually.

\section{Water content of tomato fruit}

After growth measurements with the rotary variable differential transformer, fruit size was measured with the digital caliper, and fresh weight was recorded. Fruit was cut in small pieces and kept at $70^{\circ} \mathrm{C}$ in the air circulating oven until dry weight became stable. In usual cases, dry weight was determined one week after incubation in the oven. Water content was calculated as follows;

$$
\text { Water Content }=\frac{\text { Fresh weight }- \text { Dry weight }}{\text { Fresh weight }} \times 100
$$

\section{Water status of measurement of fruit with a pressure chamber}

The matric potential in the apoplast of growing tomato fruit was measured by sealing a fruit inside a pressure chamber (Scholander et al., 1965). A single tomato fruit was sealed in a pressure chamber with the cut surface of its peduncle protruding outside, and the fruit was supported with a metal height-adjustable stand inside the pressure chamber so that fruit weight could be supported without damaging the peduncle when the peduncle was fit to the pressure chamber lid. The cut end was covered with a vial lined with wet filter paper. The pressurizing gas was humidified by bubbling through water in order to prevent dehydration of the fruit during the measurement. The external pressure was increased until the xylem solution was pushed out to the cut surface. After determination of the matric potential, the exudate was collected from the cut surface with a micro syringe by adding further external pressure, and its osmotic potential was measured with the isopiestic psychrometer (Nonami and Boyer, 1987). Immediately after the pressure chamber 


\section{GROWTH OF TOMATO FRUIT}

measurement, the fruit was taken out from the pressure chamber and placed in a humid chamber for sampling for the psychrometric measurements. Tissue of square block of about $10 \mathrm{~mm}$ length $\times 10 \mathrm{~mm}$ width $\times 2-3 \mathrm{~mm}$ thickness was sliced out from an equatorial location of the fruit, and the cut edge was coated with petroleum jelly. The tissue was placed at the bottom of the psychrometer chamber by putting the intact surface up and the cut side down.

Water status of measurement with a psychrometer

After the RGR of fruits were determined, their water status was measured by using the isopiestic psychrometer (Boyer and Knipling, 1965). This measurement prevented errors caused by the diffusive resistance of the tissue to water vapor since no net vapor exchange took place during the course of the measurement. A thermocouple chamber was coated with melted and resolidified petrolatum due to minimize water absorption (Boyer, 1967), and loaded with plant tissues immediately after excision. After the water potential $\left(\Psi_{w}\right)$ was measured, the osmotic potential $\left(\Psi_{s}\right)$ of the same tissue was immediately determined by the isopiestic psychrometer after freezing at $-70^{\circ} \mathrm{C}$ to rupture cell membranes and thawing (Ehlig, 1962). The turgor $\left(\Psi_{p}\right)$ was calculated by subtracting the osmotic potential from the water potential (Nonami et al., 1987).

\section{RESULTS}

Vessel development in pedicels

The pedicel diameter began to increase rapidly just after flowering and almost reached to the plateau on the 12th day after flowering (DAF) (Fig. 1A). The secondary xylem began to differentiate between the 4th DAF and the 8th DAF (Fig. 1C). On the 4th DAF, protoxylem vessels be-

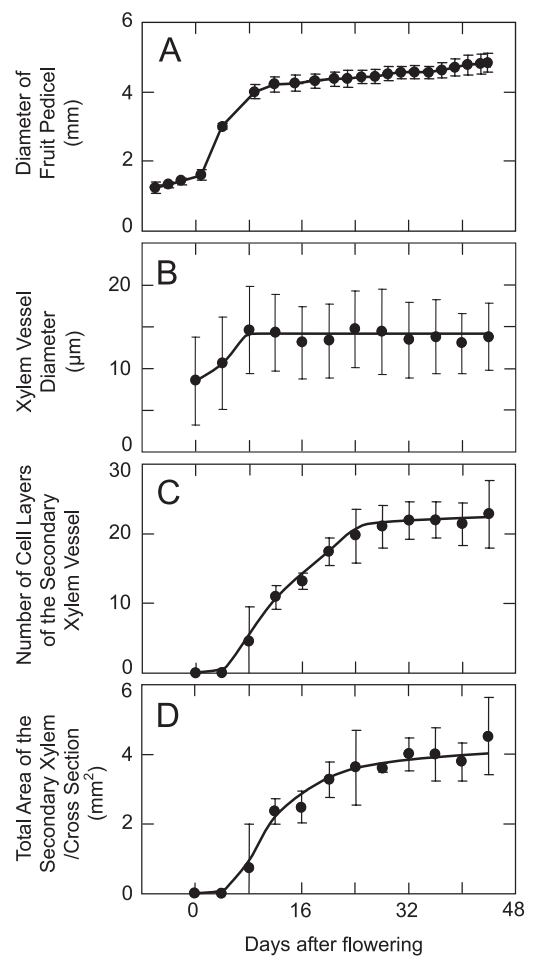

Fig. 1 Diameter (A), xylem vessel diameter (B), number of cell layers of the secondary xylem vessel (C) and the total area occupied by the secondary xylem vessel per cross-section of fruit pedicels. Vertical bars indicate 95\% confidence intervals calculated from Student's t-distribution. 
came almost collapsed, metaxylem vessels were seen clearly, and no secondary xylem vessels were observed. Safranin was fed from the peduncle which was several $\mathrm{cm}$ away from the pedicel. The metaxylem vessels were stained in red with safranin, and it is apparent that the metaxylem vessels were hydraulically conductive. On the 8th DAF, the interfascicular space disappeared, and the secondary xylem vessels were formed, connecting neighboring vascular bundles. Because the secondary xylem vessels were partially stained with safranin, it was thought that the secondary xylem became almost conductive on the 8th DAF. On the 12th DAF, most of the secondary xylem vessels were stained with safranin, indicating that they were hydraulically conductive. On the 24th DAF, the secondary xylem vessels were stained almost uniformly with safranin. This indicates that water could flow through the secondary xylem vessels in the pedicel uniformly toward the enlarging tomato fruit on the 24th DAF. Similarly, the secondary xylem vessels were stained with safranin uniformly while we were checking cross-sections of pedicels till the 44th. Thus, it was apparent that the vessels were hydraulically conductive while tomato fruit was enlarging.

The size of xylem vessel diameter increased from the 0th DAF to the 8th DAF and thereafter reached the plateau (Fig. 1B). This indicates that the size of xylem vessels could be considered almost uniform after the differentiation of the secondary xylem vessels. The number of cell layers of the secondary xylem vessels increased from the 4th DAF to the 24th DAF, then reached the plateau, i.e. approximately 23 layers (Fig. 1C). The total area of the secondary xylem vessels per cross-section of the pedicel was measured from images taken with a microscope, and plotted in Fig. 1D. It was found that an increase in the secondary xylem area contributed an increase in sizes of pedicel diameter (Figs. 1A and 1D).

Volume measurements of tomato fruit

Fruit volume was calculated with a formula for an ellipsoidal volume according to Equation 5. When fruit was cut in several pieces, there were no noticeable air spaces in cut surface. Because fruit volume measured with water-displacement method agreed well with the volume calculated from the fruit size as shown in Fig. 2, it is apparent that water did not enter fruit tissue significantly from the cut surface. Thus, the volume of fruit could be estimated accurately without excision of fruit, and hence, accurate RGRs of fruit according to Equation 6 could be determined prior to the water status measurements in the same individual fruit.

Specific gravity of tomato fruit

Fruit weight were plotted against fruit volume in Fig. 3. Both had a 1:1 relation, and the slope was approximately 1.0 (Fig. 3). Thus, tomato fruit used in the present study had specific gravity

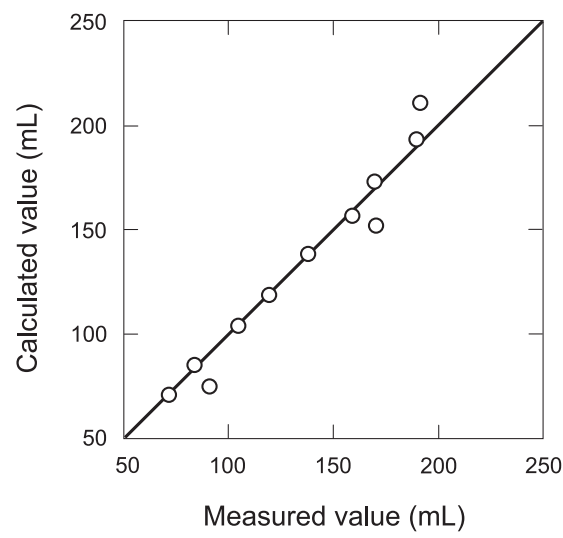

Fig. 2 Tomato fruit volume calculated with Equation 5 plotted against the volume measured. The regression line is $y=0.998 x$ and $\mathrm{r}=0.965$. 


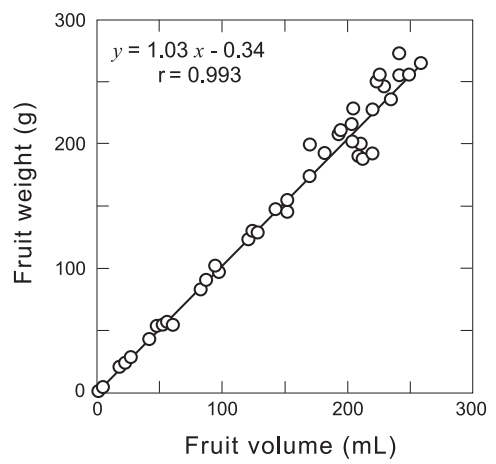

Fig. 3 Relations between fruit volume and fruit weight. The regression line is $y=1.03 x-0.34$ and $\mathrm{r}=0.993$.

of 1.0, and therefore, the fruit had almost the same weight as water of the same volume.

Growth of intact tomato fruit

After the heat-girdling and organic glue doping, the tissue was dissected, we confirmed that phloem and surrounding living tissue in the peduncle were browned, and thus, expansion growth of tomato fruit after the girdling treatment should be solely dependent on the water inflow through the xylem vessels. After the organic glue dried, the water leakage from the xylem at the heat girdling location due to evaporation should be minimized. In Fig. 4, 3 examples of growth curves are shown. At the girdling treatment (Treatment with open arrows in Fig. 4), displacement curves were shifted due to handling because the growth measurement was continued with the transformer at-

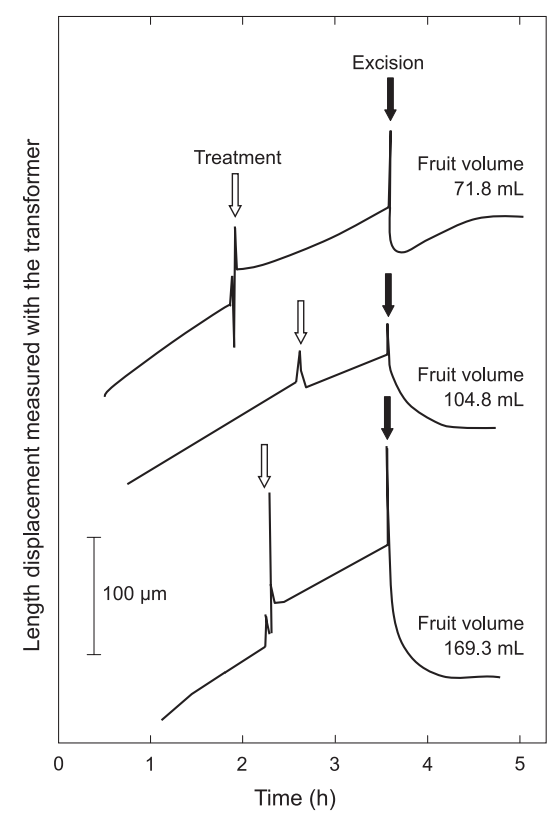

Fig. 4 Length displacement measured with the rotary variable differential transformer in tomato fruit growth while the girdling treatment and excision of its peduncle were conducted. Growth curves of three individual tomato fruit having different fruit volumes (i.e., $71.8 \mathrm{~mL}, 104.8 \mathrm{~mL}$ and $169.3 \mathrm{~mL}$ ) were shown. Open and closed arrows indicate time when the girdling and excision treatment were conducted, respectively. The vertical bar indicates $100 \mu \mathrm{m}$. 
tached while steaming and doping glue on the peduncle were being taken place. After the treatment, the expansion growth was recorded, and the growth rates did not seem to be altered significantly (Fig. 4). After excision of the peduncle (Excision with closed arrows in Fig. 4), curves were shifted downward due to handling and changes in the center of gravity of fruit after excision. Growth stopped completely $1-1.5 \mathrm{~h}$ after the excision, indicating that cell expansion in fruit was inhibited after the removal of the water source (Fig. 4). The girdling experiments conducted in the present study were summarized in Table 1 . We repeated 9 times with different sizes of fruit having 71.8 to $191.0 \mathrm{~mL}$ of volume (Table 1). Water content of fruit was $93.7 \%$ as the average, ranging from 93.0 to $94.6 \%$ (Table 1 ). When the girdling treatment was conducted, expansion rate decreased to $89.0 \%$ of the original (Table 1), indicating that most water was coming from the xylem to sustain the growth. At most, $11 \%$ of water might be originated from the phloem to sustain growth of tomato fruit. Thus, it can be concluded that the source of water for cell elongation in fruit is mostly dependent on the water inflow from the xylem vessels.

Water flow rates per vessel in pedicels

Fruit volume was measured in both fruit attached in plants and that removed from plants, and plotted together in Fig. 5A. As expected from Fig. 2, both plots overlapped each other (Fig. 5A), and fruit volume could be determined with both methods accurately. We checked with a microscope whether stomata exist on tomato fruit surface or not after formation of fruit. No stomata were found on the fruit surface, confirming the finding of Leonardi et al. (1999).

Water uptake rates per fruit were estimated from tangents of the curve shown in Fig. 5A, assuming that changes in $93.7 \%$ of fruit volume, which was the water content of the fruit, were caused solely by water entry without water loss due to evapotranspiration from fruit surface. The water uptake rate per fruit per day became the maximum on the 20th DAF (Fig. 5B).

The number of xylem vessels per pedicel cross-section was counted with time after flowering (Fig. 5C). After the 4th DAF, the number increased rapidly (Fig. 5C). This increase was associated with differentiation of the secondary xylem vessels (Fig. 1C).

Because safranin was absorbed from the cut end in the peduncle to reach the pedicel and the secondary xylem vessels in the pedicel were almost uniformly stained with safranin, it can be assumed that most xylem vessels in pedicels are hydraulically conductive. When the water uptake rate per fruit per day was divided by the number of xylem vessels per pedicel cross-section, the water flow rate per vessel per day for fruit expansion could be calculated (Fig. 5D). The water flow rate per vessel for fruit expansion became the maximum on the 12th DAF, and it became lower gradually thereafter (Fig. 5D).

Table 1 Measurements of expansion rates before (B) and after (A) girdling treatment with the rotary variable differential transformer, fruit volume, fresh weight, dry weight and water contents of tomato fruit grown hydroponically. Also, the ratio of A to B is shown. Measurements were repeated 9 times and the average $\pm \mathrm{SD}$ is also shown.

\begin{tabular}{|c|c|c|c|c|c|c|c|}
\hline \multirow{2}{*}{ No. } & \multirow{2}{*}{$\begin{array}{l}\text { Fruit Volume } \\
\qquad(\mathrm{mL})\end{array}$} & \multirow{2}{*}{$\begin{array}{c}\text { Fresh Weight } \\
(\mathrm{g})\end{array}$} & \multirow{2}{*}{$\begin{array}{l}\text { Dry Weight } \\
(\mathrm{g})\end{array}$} & \multirow{2}{*}{$\begin{array}{c}\text { Water Content } \\
(\%)\end{array}$} & \multicolumn{2}{|c|}{ Expansion Rate $\left(\times 10^{-9} \mathrm{~m} \mathrm{~s}^{-1}\right)$} & \multirow{2}{*}{$\begin{array}{c}\text { Ratio of } \\
\text { A to B (\%) }\end{array}$} \\
\hline & & & & & Before Treatment (B) & After Treatment $(\mathrm{A})$ & \\
\hline 1 & 71.8 & 70.8 & 4.53 & 93.6 & 16.50 & 15.83 & 96.0 \\
\hline 2 & 91.2 & 90.1 & 5.81 & 93.6 & 2.17 & 2.00 & 92.3 \\
\hline 3 & 104.8 & 101.4 & 6.68 & 93.4 & 14.83 & 11.17 & 75.3 \\
\hline 4 & 120.4 & 117.7 & 7.94 & 93.3 & 20.17 & 19.17 & 95.0 \\
\hline 5 & 138.2 & 123.7 & 8.70 & 93.0 & 16.00 & 9.83 & 61.5 \\
\hline 6 & 160.3 & 145.8 & 9.70 & 93.3 & 14.17 & 12.67 & 89.4 \\
\hline 7 & 169.3 & 146.1 & 9.38 & 93.6 & 14.33 & 13.67 & 95.3 \\
\hline 8 & 171.0 & 165.0 & 8.92 & 94.6 & 8.67 & 8.33 & 96.2 \\
\hline 9 & 191.0 & 182.8 & 9.88 & 94.6 & 2.33 & 2.33 & 100.0 \\
\hline \multicolumn{2}{|c|}{ Average \pm SD } & & & $93.7 \pm 0.6$ & & & $89.0 \pm 12.5$ \\
\hline
\end{tabular}




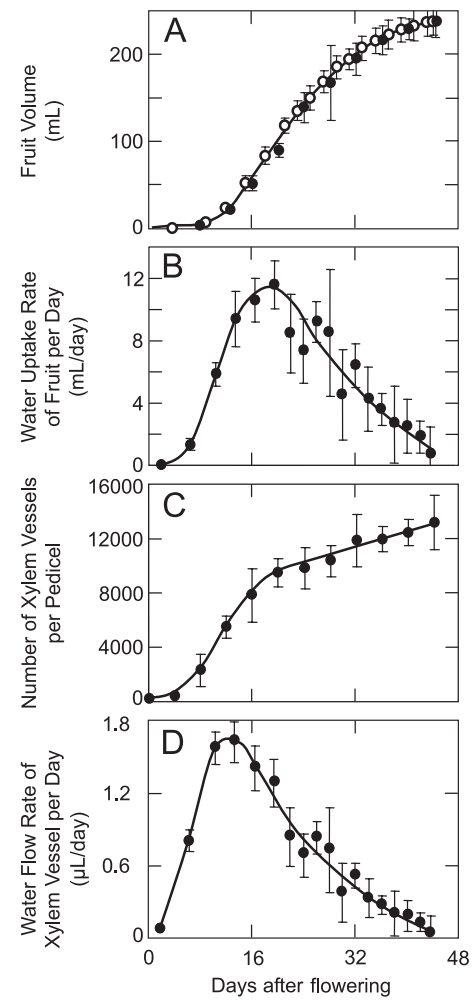

Fig. 5 Fruit volume (A), water uptake rate of fruit per day (B), number of xylem vessels per peduncle crosssection (C) and water flow rate of xylem vessel per day (D). Closed circles and open circles in A indicate volume measured in excised fruit and volume calculated from length measurements of fruit grown in tomato plants. Vertical bars indicate $95 \%$ confidence intervals calculated from Student's tdistribution.

\section{Apoplast osmotic potential of tomato fruit}

Turgor in fruit was first $0.3 \mathrm{MPa}$, and decreased gradually to $0.1 \mathrm{MPa}$ over several hours after dehydration treatment (Fig. 6A). Throughout the experiment, the osmotic potential of the apoplast solution in tomato fruit was $-0.07 \mathrm{MPa}$ (Fig. 6B). Despite turgor loss in growing fruit due to dehydration, solute concentration in the apoplast of fruit was low (Fig. 6B), indicating that the xylem solution in tomato fruit is dilute in quite wide ranges of the water status of tomato plants.

Water potentials measured with the psychrometer in fruit tissue was slightly lower than the matric potential measured with the pressure chamber (Fig. 6B). The difference between the matric potential and the water potential was equivalent to the size of the osmotic potential of the apoplast (Fig. 6B).

\section{Relationship between fruit growth and water status}

Growth curves of fruit volume exhibited a sigmoidal curve (Fig. 7A). Water potentials and osmotic potentials of pericarps exhibited the maximum at the 18th DAF, and then gradually decreased as the fruit developed (Fig. 7B). Turgor of pericarp was high at the 18th DAF, and then gradually decreased during the measurement (Fig. 7C). Since the water potential changed drastically between the 18th and the 19th DAF, data obtained before the 18th DAF were designated as the early growing stage and those obtained after the 19th DAF until the 32nd DAF as the later growing stage. 
M. M. HOSSAIN AND H. NONAMI

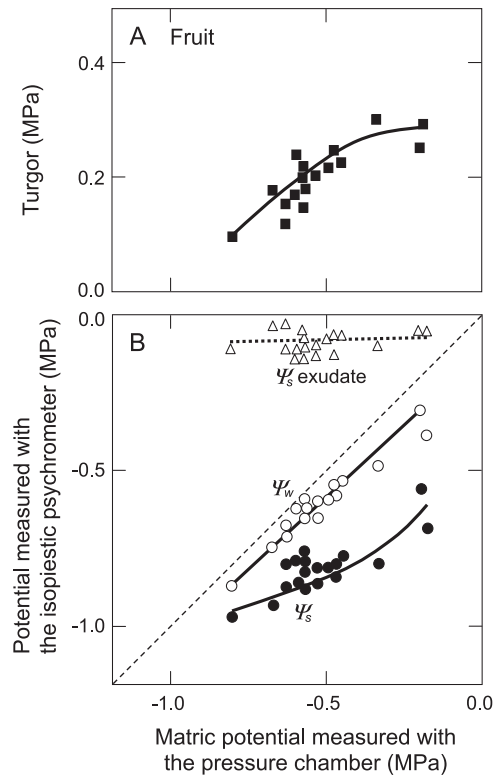

Fig. 6 Turgor (A), apoplast solute potential $\left(\Psi_{s}\right.$ exudate), water potential $\left(\Psi_{w}\right)$ and osmotic potential $\left(\Psi_{s}\right)$ measured with isopiestic psychrometers against the matric potential measured with the pressure chamber in tomato fruit $(\mathrm{B})$. Opened triangle $(\triangle)$, opened circle $(\bigcirc)$ and closed circle $(\bigcirc)$ indicate exudate water potential, water potential and osmotic potential, respectively.
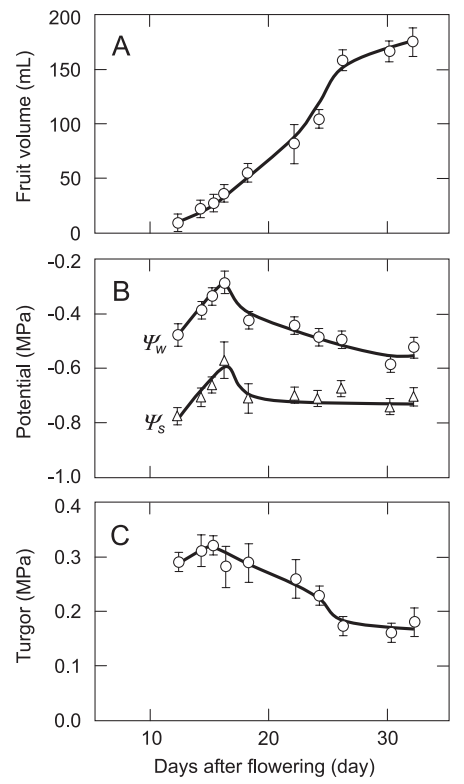

Fig. 7 Changes in fruit volume $(A)$, water potential $(\bigcirc)$ and osmotic potential $(\triangle)(B)$ and turgor $(C)$ of tomato peel grown under hydroponic culture after flowering. Vertical bars indicate the standard errors $(n=3$ to 7$)$. 


\section{GROWTH OF TOMATO FRUIT}

\section{Growth parameters of tomato fruit}

When the RGRs of fruit during the early growing stage were plotted against sizes of the growth-induced water potential, the RGRs of fruit had a linear relation with the sizes of the growthinduced water potentials through the origin (Fig. 8A). The size of the growth-induced water potentials ranged from 0.22 to $0.40 \mathrm{MPa}$. Estimated from the slope of the line, the $L$ in pericarps of tomato fruit during the early growth stage was $1.43 \times 10^{-5} \mathrm{~s}^{-1} \mathrm{MPa}^{-1}$. The relationship between the RGRs and pericarp turgor during the early stage was plotted in Fig. 8B. Plots formed by the RGRs and turgor were vertically overlapping each other in terms of the $\mathrm{x}$ axis, and thus the $m$ was set to $+\infty$. From the intercept at the $\mathrm{x}$-axis, the $Y$ of pericarp turgor during the early growing stage was estimated to be $0.30 \mathrm{MPa}$, which was obtained as the average of turgor values. The size of the growth-effective turgor was negligibly small (Fig. 8C).

During the later fruit growing stage, plots formed by the RGRs and the growth-induced water potential distributed vertically in terms of the $\mathrm{x}$ axis, considering the $L$ to be infinitely large. Thus, the growth-induced water potential was not considered as a limiting factor for cell expansion in tomato fruit in the later stage. On the other hand, the regression line formed by the RGRs and turgor had a positive slope (Fig. 8E). The $Y$ and $m$ of the pericarp during the later growing stage was estimated to be $0.12 \mathrm{MPa}$ and $1.33 \times 10^{-5} \mathrm{~s}^{-1} \mathrm{MPa}^{-1}$ (Figs. $8 \mathrm{E}$ and $8 \mathrm{~F}$ ).

These results indicate that the dominant factor affected on tomato fruit growth is the growthinduced water potential during the early growth stage and the growth-effective turgor during the late growth stage.

\section{DISCUSSION}

\section{Predominant water flow through the xylem}

Entry of water into fruit is determined by two fluxes: water inflow and assimilate inflow. Ho et al. (1987) suggested that over $90 \%$ of the water entering the tomato fruit may enter through the phloem. We tested a possibility of water entry through the phloem with the girdling treatment in intact tomato plants. Girdling treatment was conducted with heating (Ehret and Ho, 1986; Grange and Andrews, 1994) and the application of the organic glue. The organic glue contained $40-50 \%$ of cyclohexanone, which is a solvent for cellulose acetate, nitrocellulose, natural resins, waxes and fats, and $35-45 \%$ of methyl ethyl ketone, which is a solvent for synthetic resins (Windholz, 1976). Since the organic solvent can easily permeate cell walls and membranes, the glue should destroy

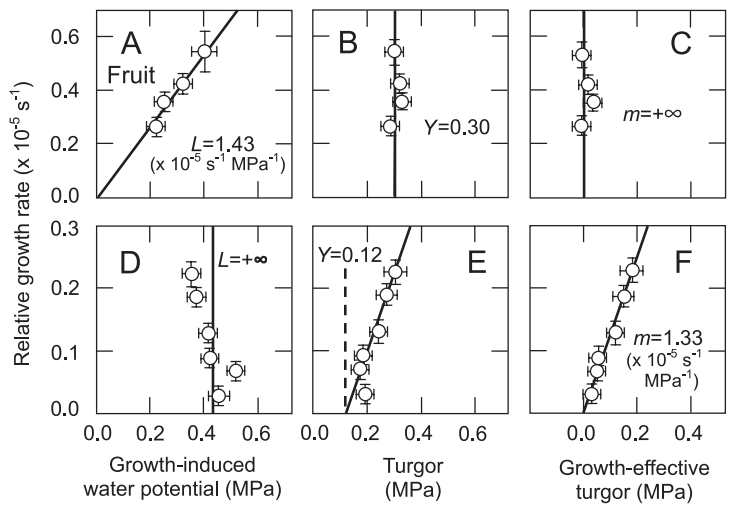

Fig. 8 Relative growth rate plotted against sizes of the growth-induced water potential (A, D), peel turgor (B, E) and growth-effective turgor $(\mathrm{C}, \mathrm{F})$ of tomato fruit. Each point in A-C was calculated from data taken between the 12th and 16th DAF. Each point in D-F was calculated from data taken between the 18th and 32nd DAF. Vertical and horizontal bars indicate the standard errors $(n=3$ to 7$)$. 
the membrane structure in plant cells. Additionally, dried glue could cover the location of heatgirdling, and thus, evaporation from the xylem tissue should be minimized by this coverage. Simultaneous treatments with heat and organic solvents must destroy living cells in the peduncle, and the damage was confirmed by checking the tissue dissected. The girdling treatment was conducted between 2:00 and 3:00 a.m., and then the air humidity was between 85 and 98\% RH in the greenhouse. Under these conditions in the dark, stomata of the tomato plant must be relatively closed, and transpiration must be very small, then the fruit growth of the girdled plants was reduced only to approximately $90 \%$ of the ungirdled fruit (Table 1). In this situation, most of water for cell expansion in tomato fruit must be originated from the xylem.

Windt et al. (2009) revealed that most water in the tomato truss was imported through the xylem but not from the phloem. They used MRI for water flow measurements when the tomato fruit truss was set in MRI magnet. They concluded that at least $75 \%$ of the net influx into the fruit occurred through the external xylem and about $25 \%$ via the perimedullary region, which contains both phloem and xylem (Windt et al., 2009). Our findings agree with results of Windt et al. (2009).

In some cases, the girdling treatment reduced growth of tomato fruit significantly when the treatment was conducted in the daytime (Ehret and Ho, 1986; Grange and Andrews, 1994). During the daytime, reduction of fruit growth of the girdled plants was significant although the ungirdled plants had highest growth rates in fruit during the day (Ehret and Ho, 1986). Thus, transpiration must be affecting the water flow in fruit of tomato plants. In the present study, the effect of transpiration was minimized by conducting the growth measurement in the dark with the girdling treatment. Additionally, the growth measurement in the dark had some advantage for the accuracy due to avoidance of direct irradiation on the transformer and the setups by the sun. Because the transformer and major parts of the setup to support the tomato fruit were made of metals, direct irradiation on such setups in the daytime might cause heat expansion in the instrumentation due to the radiant heat, resulting in significant errors for measurements. We avoided such a possibility in the present study. Furthermore, the fruit expansion rate was measured with the bagged fruit, and the loss of water from the fruit was negligible. Therefore, tomato fruit expansion process can be explained from the viewpoint of water flow into fruit from the water source associated with the water status in fruit.

\section{Predominant growth-control parameters for developing tomato fruit}

The water source of fruit expansion should be the xylem connecting to fruit. The apoplast solution in the fruit was extracted with a pressure chamber, and solute concentration was dilute (Fig. $6 \mathrm{~B})$. Additionally, the matric potential was determined prior to the apoplast solution extraction, and then compared with the water potential measured with the isopiestic psychrometer (Fig. 6B). In this study, water potential and osmotic potential in isolated pericarp were measured by the isopiestic psychrometer. There is a criticism that any growing tissue presumably continue to grow until the turgor be lowered to the threshold in the psychrometer chamber (Cosgrove et al., 1984). However, many reports showed that the water status of intact and excised tissues had been compared and found to be similar (Boyer, 1968; Boyer and Wu, 1978; Cavalieri and Boyer, 1982; Nonami and Boyer, 1989; Ikeda et al., 1999a). Nonami et al. (1987) and Ikeda et al. (1999a) made a comparison of turgor measured by the isopiestic psychrometer and a pressure probe method in the soybean seedlings and soybean embryos, respectively, and similar values were obtained with both methods. The osmotic potentials of pericarp during the fruit development, which showed about $-0.75 \mathrm{MPa}$, were obtained similar the results reported by Shackel et al. (1991).

The water status of the apoplast can be written as follows;

$$
\Psi_{w}^{a p o}=\Psi_{s}^{a p o}+\Psi_{m}
$$

where $\Psi_{w}^{a p o}, \Psi_{s}^{a p o}$ and $\Psi_{m}$ are the water potential, osmotic potential and matric potential in the apoplast, respectively. Figure 6 confirmed the relation of Equation 7, and thus, the accurate water 


\section{GROWTH OF TOMATO FRUIT}

status could be measured in tomato fruit with both the psychrometer and the pressure chamber in the present study. Similar relation was confirmed by Nonami and Boyer (1987) in the zone of elongation of actively growing intact soybean and pea seedlings with the pressure chamber and the isopiestic psychrometer. The apoplast osmotic potentials in soybean and pea seedlings were $-0.041 \mathrm{MPa}$ and $-0.028 \mathrm{MPa}$, respectively (Nonami and Boyer, 1987). Thus, the major component of water potential in expanding tomato in Equation 7 was the matric potential, which is the negative pressure. Because measurement principles of the pressure chamber and the psychrometer are different, cross-checking by using individual same fruit with both instrumentation proved that the water status measured in tomato fruit was accurate. Since measurements of the matric potential with the pressure chamber required several minutes to complete, it is safe to say that errors due to wall relation expected in the psychrometric sampling should not be significant although water potential measurements with the psychrometer took several hours.

Some investigators estimated the bulk tomato turgor to be less than $0.2 \mathrm{MPa}$ (Johnson et al., 1992; Grange, 1995). Shackel et al. (1991) reported that pericarp turgor in mature tomato fruit was less than $0.2 \mathrm{MPa}$ by directly measuring with a pressure probe. Similarly, the pericarp turgor obtained with the isopiestic psychomotor was less than $0.2 \mathrm{MPa}$ after $26 \mathrm{DAF}$. However, the pericarp turgor during the early growth stage showed slightly higher than those during the late growth stage. In the early growth stage, the growth-effective turgor was negligibly small although turgor was relatively high. Additionally, $m$ was significantly larger than $L$ in expanding fruit at the early growth stage. Thus, when $m \gg L$, the coefficient of Equation 3 can be modified as follows;

$$
\frac{m L}{m+L} \approx \frac{m L}{m}=L
$$

Furthermore, sizes of the growth-induced water potential were much larger than those of the growth-effective turgor, which was near zero, i.e., $\left(\Psi_{o}-\Psi_{w}\right) \gg\left(\Psi_{p}-Y\right) \approx 0$. By using the above approximation, Equation 3 can be modified as follows;

$$
G=\frac{m L}{m+L}\left\{\left(\Psi_{o}-\Psi_{w}\right)+\left(\Psi_{p}-Y\right)\right\} \approx L\left(\Psi_{o}-\Psi_{w}\right)
$$

Thus, Equation 3 can be approximated to be equivalent to Equation 2 when the growth parameters were measured in tomato fruit in the early growth stage.

On the other hand, during the late growth stage in developing fruit, $L$ was considered significantly larger than $m$. Thus, when $L \gg m$, the coefficient of Equation 3 can be modified as follows;

$$
\frac{m L}{m+L} \approx \frac{m L}{m}=m
$$

Furthermore, sizes of the growth-effective turgor were much larger than those of the growthinduced water potential, which was near zero, i.e., $\left(\Psi_{p}-Y\right) \gg\left(\Psi_{o}-\Psi_{w}\right) \approx 0$. By using the above approximation, Equation 3 can be modified as follows;

$$
G=\frac{m L}{m+L}\left\{\left(\Psi_{o}-\Psi_{w}\right)+\left(\Psi_{p}-Y\right)\right\} \approx m\left(\Psi_{p}-Y\right)
$$

Thus, Equation 3 can be approximated to be equivalent to Equation 1 when the growth parameters were measured in tomato fruit during the late growth stage. We estimated that $Y$ of pericarp during the late growth stage was $0.12 \mathrm{MPa}$. This is in agreement with the results reported by Grange (1995) suggested that $Y$ of tomato pericarp tissue was about $0.1 \mathrm{MPa}$.

Interactions between the growth-induced water potential and the growth-effective turgor

It is known that cell division in tomato fruit is usually completed about 10 DAF (Saito, 1989; Ho, 1992). Thus, tomato fruit growth after $10 \mathrm{DAF}$ is primarily due to cell expansion in fruit. 
Growth in the pedicel diameter decelerated quickly after 10 DAF. The average xylem vessel diameter in fruit pedicel increased until 8 DAF. When the secondary xylem vessels differentiated after $8 \mathrm{DAF}$, the size of xylem vessel diameter became almost uniform. Additionally, the number of cell layers of the secondary xylem vessels per pedicel cross-section was increasing during the early growth stage of tomato fruit. Thus, conductive vessels were still under differentiating stage during the early growth stage of fruit. In the early growth stage of tomato fruit, i.e., a period before the 18th DAF, the growth-induced water potential was a regulating factor for growth.

The growth-induced water potential was found to be a regulating factor for cell elongation in soybean hypocotyls (Boyer and Wu, 1978; Cavalieri and Boyer, 1982; Nonami and Boyer, 1987, 1993; Nonami et al., 1997), pea epicotyls (Nonami and Boyer, 1987), tissue cultured embryos and tissues (Ikeda et al., 1999a), the zone of elongation of maize leaves (Westgate and Boyer, 1984) and the zone of elongation of Festuca arundinacea leaves (Martre et al., 2001). Vascular systems in the zone of elongation of those plants were differentiating and developing while the growthinduced water potential was associated with processes of cell elongation. In the zone of elongation of soybean hypocotyls, the diffusivity for water was measured with the pressure probe in small cells near xylem vessels, and it was found that the diffusivity for water was much less in the small cells than in the outlying cells (Nonami et al., 1997). The small cells thus were a barrier that caused the growth-induced potential difference to be large during rapid growth (Nonami et al., 1997). In case of the early growth stage of tomato fruit, it is likely that formation of the growthinduced water potential was also associated with processes of vascular system development in fruit and pedicels. Additionally, demand of water uptake for fruit growth was relatively high in the early growth stage, and the water flow rate per xylem vessel per day increased and reached the maximum on the 12th DAF. As differentiation of the secondary xylem vessel proceeded, the water flow rate per xylem vessel per day decreased, and when growth stage advanced along the vessel differentiation to the later growth stage in fruit, the growth-induced water potential and hydraulic conductance were not regulating factors for fruit expansion any longer.

Unlike stems and roots, the zone of elongation is not located in specific area in fruit and the whole tissue continues to expand almost uniformly in all directions (Grange, 1995). Furthermore, growth of fruit continues even after differentiation and development of vascular systems are almost completed in pedicels, and growth period in fruit is usually longer than 40 days in tomatoes. In the present study, it was found that the growth-effective turgor was a regulating factor for growth in the later growth stage of tomato fruit when vascular systems in pedicels were almost completely developed. Grange (1995) measured bulk turgor of tomato fruit of about $30 \mathrm{~mm}$ diameter on the 25th DAF, and turgor was about $0.2 \mathrm{MPa}$ in fruit from plants that were fully turgid. Pericarp tissues were excised and isolated from actively growing fruit, and the rate of tissue growth was measured with turgor of pericarp slices in various incubation media (Grange, 1995). It was found that yield threshold was about $0.1 \mathrm{MPa}$ and cell elongation rates were proportionally increased between about $0.1 \mathrm{MPa}$ and $0.4 \mathrm{MPa}$ of turgor (Grange, 1995). We obtained the similar results in fruit of the same age as Grange (1995) observed in isolated pericarp tissues.

When tomato fruit becomes the mid-size, it is frequent to observe fruit cracking (Saito, 1988). Large tomato fruit have been found to be more prone to concentric and radial cracks (Koske et al., 1980). Peet and Willits (1995) noted that tomato fruit are most sensitive to cracking at the start of ripening. Ikeda et al. (1999b) induced fruit cracking of single-truss tomato plants of the same cultivar as in the present study on the 24th DAF when they were grown hydroponically. Fruit cracking of the same cultivar occurred rarely before the 20th DAF according to Ikeda et al. (1999b) (additional personal communication). This timing of the initiation of fruit cracking seems to be coincided to changes in the water status of fruit after the 18th DAF in the present study. After passing the 18th DAF, the growth-effective turgor and $m$ were the limiting factors for growth. In the later growth stage of fruit, vascular systems in pedicels were well developed, and water may enter 


\section{GROWTH OF TOMATO FRUIT}

rapidly into fruit when evaporative demand changes suddenly. When fruit pruning substantially increased the plant leaf/fruit ratio, the incidence of cracking increased significantly (Ehret et al., 1993). In sliced pericarp tissues taken from actively growing fruit of the 25th DAF, high turgor induced by changing incubation media decreased cell elongation rates (Grange, 1995). This observation may suggest that sudden water entry in elongating cells in tomato fruit may inhibit cell elongation and stiffen cell walls simultaneously. Such an abrupt change in cell turgor may result in fruit cracking in the later stage of tomato fruit. Because fruit cracking was caused by physical rupture in fruit tissue, it is apparent that cell turgor must play a central role for this abnormality in fruit growth during the later growth-stage.

We thank K. Sumida, T. Kanamoto, M. Kamei, H. Wada and T. Fukuyama for their assistances for this study.

\section{REFERENCES}

Boyer, J. S. 1967. Leaf water potential measured with a pressure chamber. Plant Physiol. 42: 133-137.

Boyer, J. S. 1968. Relationship of water potential to growth of leaves. Plant Physiol. 43: 1056-1062.

Boyer, J. S., Knipling, E. B. 1965 . Isopiestic psychrometer for measuring leaf water potentials with a thermocouple psychrometer. Proc. Natl. Acad. Sci. USA 54: 1044-1051.

Boyer, J. S., Wu, G. 1978. Auxin increases the hydraulic conductivity of auxin-sensitive hypocotyls tissue. Planta 139: 227-237.

Cavalieri, A. J., Boyer, J. S. 1982. Water potentials induced by growth in soybean hypocotyls. Plant Physiol. 69: $492-496$.

Cosgrove, D. J. 1993. Wall extensibility: its nature, measurement and relationship to plant cell growth. Tansley Review No. 46. New Phytologist 124: 1-23.

Cosgrove, D. J., van Volkenburgh, E., Cleland, R. E. 1984. Stress relaxation of cell walls and the yield threshold for growth: demonstration and measurements by micropressure probe and psychrometer techniques. Planta 162: 46-52.

Ehlig, C. F. 1962. Measurement of energy status of water in plants with a thermocouple psychrometer. Plant Physiol. 37: 288-290.

Ehret, D. L., Ho, L. C. 1986 . Effects of osmotic potential in nutrient solution on diurnal growth of tomato fruit. J. Exp. Bot. 37: 1294-1302.

Ehret, D. L., Helmer, T., Hall, J. W. 1993. Cuticle cracking in tomato fruit. J. Hort. Sci. 68: 195-201.

Grange, R. I. 1995. Water relations and growth of tomato fruit pericarp tissue. Plant, Cell Environ. 18: 13111318.

Grange, R. I., Andrews, J. 1994. Expansion rate of young tomato fruit growing on plants at positive water potential. Plant, Cell Environ. 17: 181-187.

Green, P. B., Erickson, R. O., Buggy, J. 1971. Metabolic and physical control of cell elongation rate: in vivo studies in Nitella. Plant Physiol. 47: 423-430.

Ho, L. C. 1992. Fruit growth and sink strength. In "Fruit and Seed Production. Aspects of Development, Environmental Physiology and Ecology” (ed. by Marshall, C., Grace, J.), Society for Experimental Biology Seminar Series 47, Cambridge University Press, Cambridge, p 101-124.

Ho, L. C., Grange, R. I., Picken, A. J. 1987. An analysis of the accumulation of water and dry matter in tomato fruit. Plant, Cell Environ. 10: 157-162.

Houghtaling, H. B. 1935. A developmental analysis of size and shape in tomato fruits. Bull. Torrey Bot. Club 62: $243-252$.

Ikeda, T., Nonami, H., Fukuyama, T., Hashimoto, Y. 1999a. Hydraulic contribution in cell elongation of tissue-cultured plants: growth retardation induced by osmotic and temperature stresses and addition of 2, 4dichlorophenoxyacetic acid and benzylaminopurine. Plant, Cell Environ. 22: 899-912.

Ikeda, T., Sakamoto, Y., Watanabe, S., Okano, K. 1999b. Water relations in fruit cracking of single-truss tomato plants. Environ. Control Biol. 37: 153-158.

Johnson, R. W., Dixon, M. A., Lee, D. R. 1992. Water relations of the tomato during fruit growth. Plant, Cell 


\section{M. HOSSAIN AND H. NONAMI}

Environ. 15: 947-953.

Koske, T. J., Pallas, J. E., Jones, J. B. 1980. Influence of ground bed heating and cultivar on tomato fruit cracking. HortScience 15: 760-762.

Leonardi, C., Baille, A., Guichard, S. 1999. Effects of fruit characteristics and climatic conditions on tomato transpiration in a greenhouse. J. Hort. Science Biotech. 74: 748-756.

Leonardi, C., Baille, A., Guichard, S. 2000. Predicting transpiration of shaded and non-shaded tomato fruits under greenhouse environments. Scientia Hort. 84: 297-307.

Lockhart, J. A. 1965a. An analysis of irreversible plant cell elongation. J. Theor. Biol. 8: 264-275.

Lockhart, J. A. 1965b. Cell extension. In: "Plant Biochemistry" (ed. by Bonner, J., Varner, J. E.). Academic Press, New York, p 826-849.

Martre, P., Conchard, H., Durand, J.-E. 2001. Hydraulic architecture and water flow in growing grass tillers (Festuca arundinacea Schreb.). Plant, Cell Environ. 24: 65-76.

Molz, F. J., Boyer, J. S. 1978. Growth-induced water potentials in plant cells and tissues. Plant Physiol. 62: 423-429.

Nonami, H., Boyer, J. S. 1987. Origin of growth-induced water potential: solute concentration in low in apoplast of enlarging tissues. Plant Physiol. 83: 596-601.

Nonami, H., Boyer, J. S. $\quad 1989$. Turgor and growth at low water potentials. Plant Physiol. 89: 798-804.

Nonami, H., Boyer, J. S. 1993. Direct demonstration of a growth-induced water potential gradient. Plant Physiol. 102: 13-19.

Nonami, H., Boyer, J. S., Steudle, E. 1987. Pressure probe and isopiestic psychrometer measure similar turgor. Plant Physiol. 83: 592-595.

Nonami, H., Schulze, E.-D. 1989. Cell water potential, osmotic potential, and turgor in the epidermis and mesophyll of transpiring leaves: Combined measurements with the cell pressure probe and nanoliter osmometer. Planta 177: 35-46.

Nonami, H., Wu, Y., Boyer, J. S. 1997. Decreased growth-induced water potential: a primary cause of growth inhibition at low water potentials. Plant Physiol. 114: 501-509.

Peet, M. M., Willits, D. H. 1995. Role of excess water in tomato fruit cracking. HortScience 30: 65-68.

Saito, T. 1988. Growth stages and physiological ecology of tomato plants (Japanese text). In "Rural Culture Association" (ed.). Tomato: Vol. 2 of Encyclopedia of Horticultural Vegetable Crops, 528 pages, (ISBN: 9784540880629), Rural Culture Association, Tokyo, Japan, p. 21-170.

Shackel, K. A., Greve, C., Labavitch, J. M., Ahmadi, H. 1991. Cell turgor changes associated with ripening in tomato pericarp tissue. Plant Physiol. 97: 814-816.

Shirazi, A., Cameron, C. 1993. Measuring transpiration rates of tomato and other detached fruit. HortScience 28: $1035-1038$.

Scholander, P. F., Hammel, H. T., Bradstreet, E. D., Hemmingsen, E. A. 1965. Sap pressure in vascular plants. Science 148: 339-346.

Steudle, E., Wieneke, J. 1985 Changes in water relations and elastic properties of apple fruit cells during growth and development. J. Am. Soc. Hort. Sci. 110: 824-829.

Westgate, M. E., Boyer, J. S. 1984. Transpiration and growth-induced water potentials in maize. Plant Physiol. 74: 882-889.

Windholz, M. 1976. The Merck Index: An encyclopedia of chemicals and drugs. 9th ed., Merck \& Co., Inc., Rahway, N. J., USA, pp 1313.

Windt, C. W., Gerkema, E., Van As, H. 2009. Most water in the tomato truss is imported through the xylem, not the phloem: A nuclear magnetic resonance flow imaging study. Plant Physiol. 151: 830-842. 